\title{
Tunnels between continents
}

\author{
Dr. Håvard Østlid \\ HO Consult, Fetsund, Norway \\ havard.ostlid@gmail.com
}

\begin{abstract}
Future transport may have to reduce the use of energy, especially the use of fossil fuels, this points towards reduction of transport by ships, aeroplanes and cars.

Trains are a well documented way of transporting large volumes of goods as well as persons and it is assumed that the total use of energy would be very much lower than the earlier alternatives.

Furthermore, the savings of surface area, airports and roads, would be considerable, the reduction of noise as well.

Train connections across oceans and across wide bays and lakes, presents interesting possibilities of making present and future transport more efficient

By this paper the author hopes to raise interest for these promising and challenging possibilities.
\end{abstract}

The proposed design of the tunnels may be seen on internet link below, page 10, the tunnel construction and challenges will be discussed in broad terms in this paper.

Keywords: Tunnel, continents, crossing, deep sea, MAGLEV

\section{Introduction}

Oceans are a great obstacle to transport of both goods and people and may only be crossed by aeroplanes and ships.

Aeroplanes provide fast crossings over long distances, but as environmental effects are becoming more important a search for transport alternatives will be aimed at increasingly protecting the environment.

Airports require large areas to operate planes and as populations increase so does the required areas.

The noise, pollution and use of fossil fuels are adding to the problems of air transport and it seems the lobbying against air transport is constantly increasing.

One promising development in air transport may be electrical engines in large passenger planes in future.

Ships are using fossil fuels and represent serious pollution problems and transport across the oceans is slow.

This paper attempts to present an alternative to cross the oceans and wide bays by a system of three tunnels located below sea level, perhaps 200-300 meters, and using MAGLEV trains with speed as high as practically possible at the time.

The reasons for three tunnels are requirements for the tunnels to be "forever open"

One tunnel closed the other two runs as normal as outlined in several EU research projects. 


\section{Proposed concept}

Figure 1. gives an idea of possible crossings globally, this is of course only to illustrate the general idea.

A detailed study of a few places for crossings would be interesting, but political reactions might however complicate such studies.

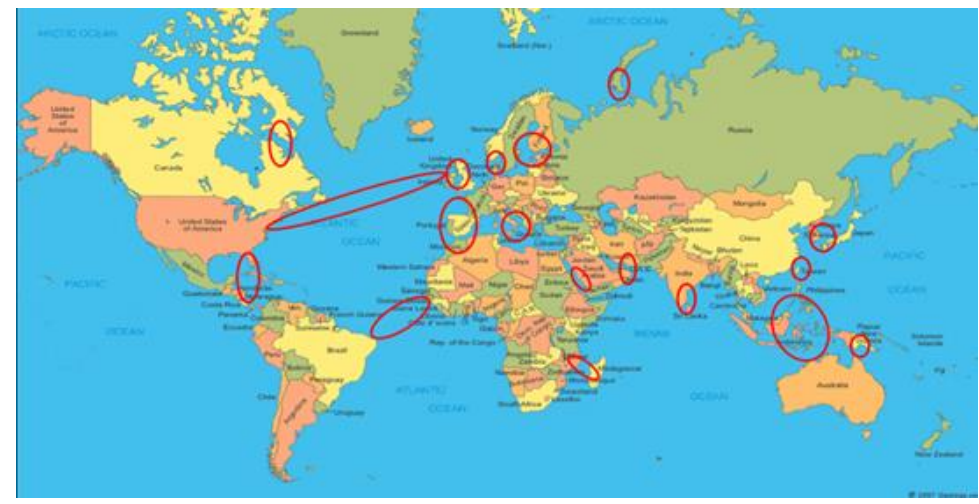

Fig. 1 Possible areas of ocean crossings

In Figure 2. the tunnel arrangement is shown with some short comments.

The three tunnels are connected by crossover tunnels located at intervals, these tunnels will serve as escape possibilities and also contain the nuclear power stations providing necessary power for the MAGLEV trains.

The crossover tunnels also have housings for the thrusters keeping the tunnels in the position in the sea.

Reduced air pressure in the tunnels will be beneficial, these and a large number of other issues have to be studied later.

The position of the tunnels below sea level will be defined by considering effects by currents and waves, lengths of anchors from biggest ships, and any other activity deemed important.

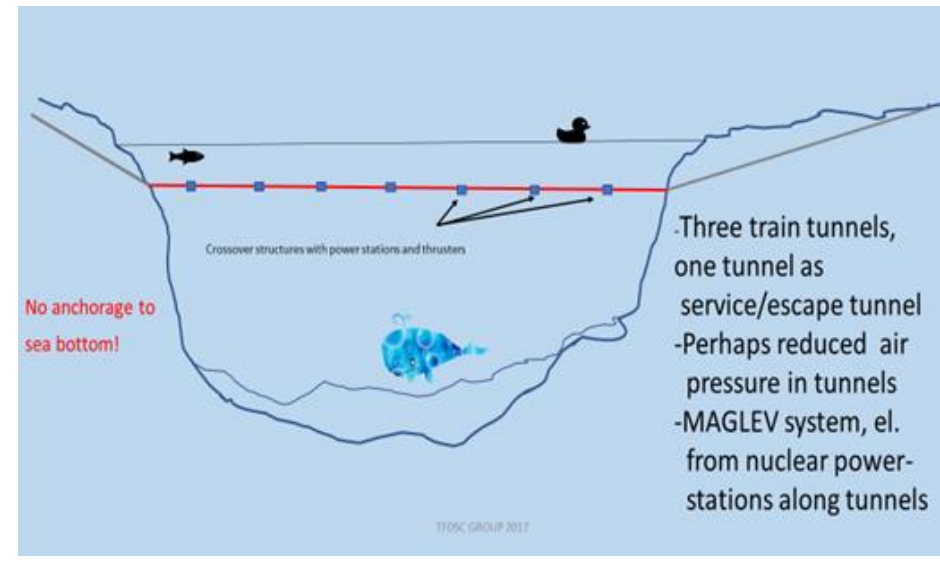

Fig.2 Principle of deep sea crossing

\section{The submerged floating tunnel (sft)}

The Høgsfjord Project, Norway, was a study of a concrete crossing of a fjord on the west coast and included extensive research and development projects for about 15 years.

This was a completely new type of structure and called for both national and international consulting work and other countries also became involved in this new structure, especially Japan, Italy and China. 
The Høgsfjord project was initiated and carried out by The Norwegian Public Road Administration, Road Research Laboratory and was finalized by complete tender documents on four alternatives approved by the Norwegian Public Roads Administration.

These alternatives were developed together with four Norwegian contractors and a large number og consultants and contained detailed designs of the SFT.'

The project was not executed due to political and financial reasons.

These studies and projects are the background for the tunnel system proposed in this paper, and the principle of SFT may be seen in Fig.4.
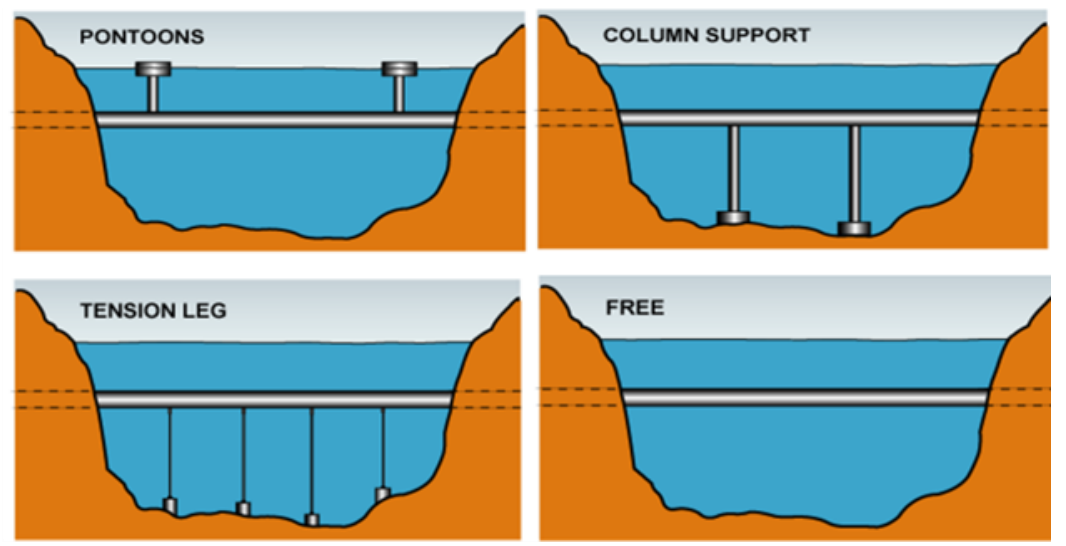

Fig.4 The four alternatives for Submerged Floating Tunnels (SFT)

\section{The proposed concept for deep sea crossings}

In Fig 5 the system of three tunnels for MAGLEV trains is shown.

The tunnels are identical, and trains may operate in all three while one tunnel will act as escape or maintenance possibility, this will give increased possibility for two tunnels in operation at all time and meeting the EU regulation for "Forever Open Roads".

The structure is kept in the desired position by thruster arrangements as shown in Fig.5, such systems have proven to be reliable for many years, notably for ships and oil platforms.

As trains approach the thrusters will adjust to the increased weight and keep the structure at the predetermined depth and opposite reaction when trains have past.

This system will of course require backups and extra capacity and extensive research and full scale testing over several years and may be the most important challenge of the whole project.

Bearing in mind the long experience with thruster systems, there is no apparent reason for this to not to be possible.

Electricity for MAGLEV and many other systems and installations may be produced by nuclear power stations located at intervals along the tunnels.

Nuclear power stations have been operated in ships and submarines for many years and safety in operation is proven to be very good and there should be no reason not to use such an arrangement.

Looking at the tunnels in Fig. 5 a large number of questions come to mind and a few are listed below and a short comment is attached where it is possible. 


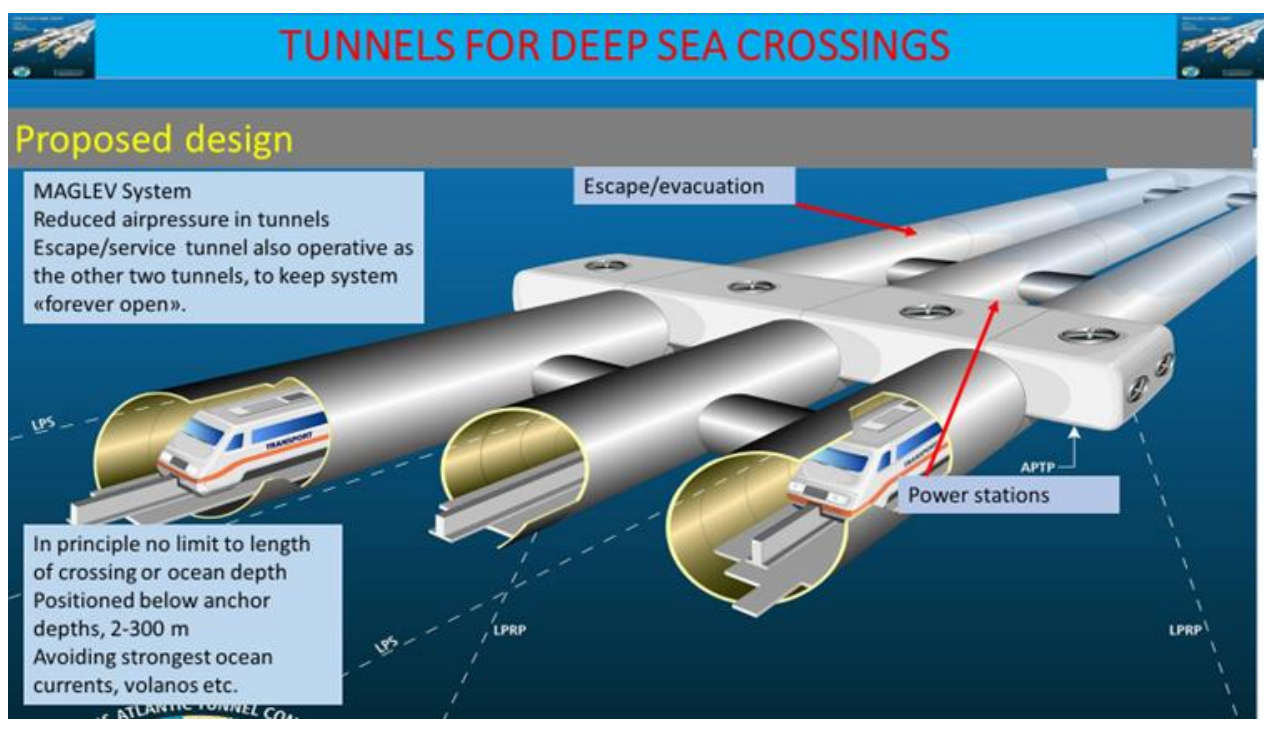

Fig 5 The proposed system for deep sea crossing

\section{A brief discussion}

- Why should we want such a system?

It is assumed that a lot of sea and air transport would be considerably reduced resulting in less use of fossil fuels and reduction of pollution.

Trains also will have stations within cities underground and take little space on the surface, perhaps areas for present day transport may be free for other developments.

Air transport creates noise and this will be greatly reduced although electric planes will undoubtedly improve this situation in future.

- Can such a system be safe?

Nuclear powerstations along the tunnels may cause many worries for a lot of people and if there is a better alternative it should be used.

Whether it is possible to use land based powerstations and feed electricity enough or very long tunnels is not known to the author, perhaps other possibilities of producing power will come in future.

Safety of complex structures and for example aeroplanes have increased as the complexities of these objects have increased and safety at present is very impressive indeed.

Safety of the proposed tunnel system will depend on a large number of factors ranging from quality and integrety of persons in research teams, sufficient financing, leadership and many other factors that will vary with time. The final approval of such a system will be a real challenge, perhaps on the level of the Appollo Project.

But the problems and challenges should not stop anybody not to think about the possibilities such a system could offer to global transport.

A short list of some topics of safety could be:

- Explosion, accident

- Terrorism, all types, outside-inside

- Fire

- Nuclear power station malfunction, powercut

- Malfunction of positioning systems

- Water ingress, local or on a large scale

- Noise problems inside tunnels 
- Airpressure problems, inside-outside trains

- Trainstation closed onshore

- Earthquakes

- Tsunamies

- Volcanos

- Change in water densities, temperatures

- Change in sea currents

- Collision with submarines

Other challenges might be:

- Financing system, agreements, guaranties

- Political situation on both landings change

- War situations

- Funds for continuos operation and maintenance

- Environmental impacts on marine life, noise and vibrations

- Any type of pollution from structure

- Impact on global material production during construction period, steel, concrete, aluminium, other metals and materials.

- Public do not want to use the trains, risk too big

- Keeping test periods sufficiently long, pressure on starting normal operation

- Airpressure from trains used for some useful purpose

- Dissipation of airpressure approaching stations. (Used to push the other train in opposite direction?

- May be start this operation long before train arrives at end station)?

- Use MAGLEV`s ability to negotiate steep gradients near station, not necessary to construct large protecting structures against ships and anchor problems.

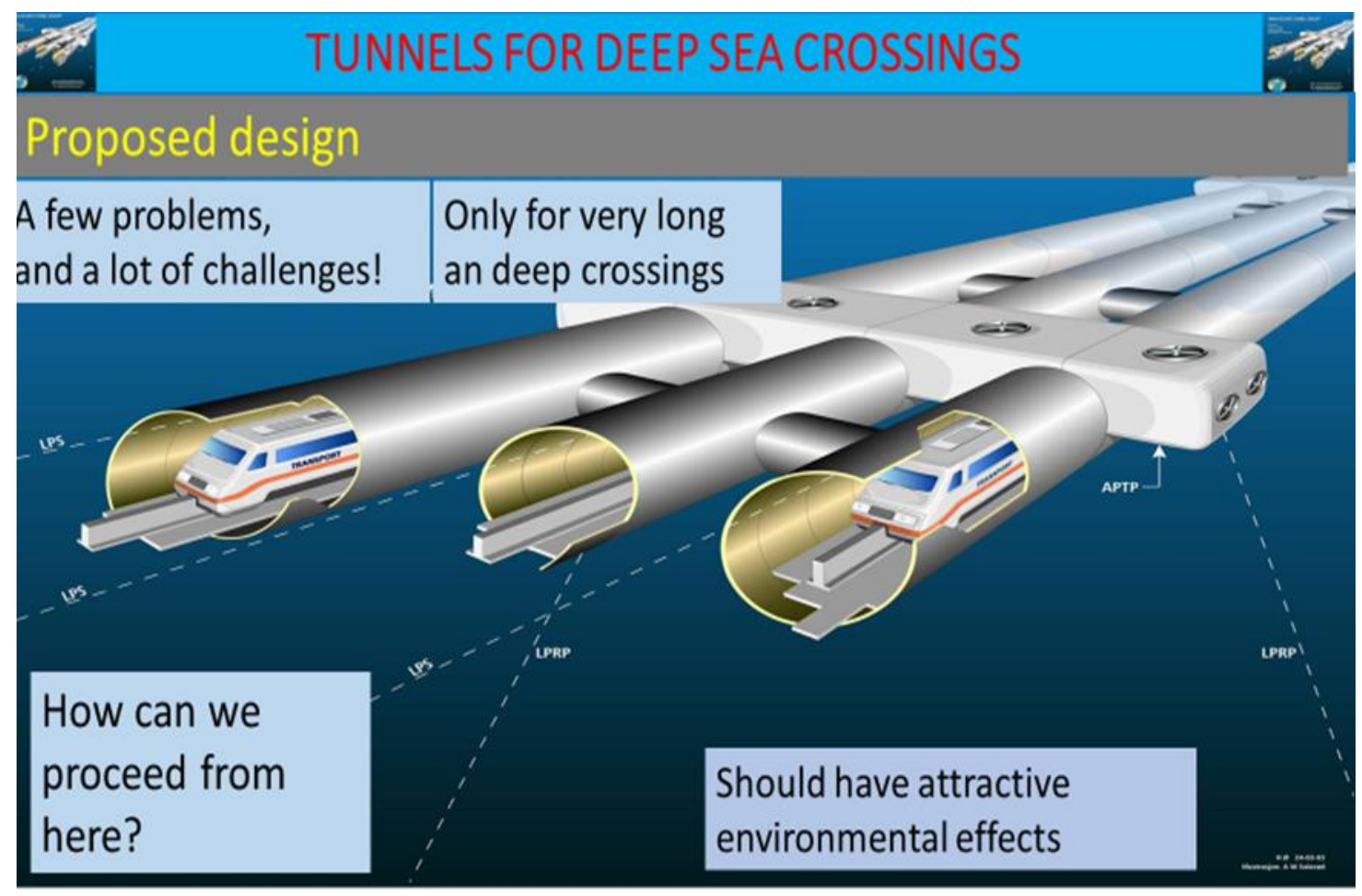

Fig. 6 One alternative and there may be many other alternatives 


\section{Acknowledgement}

I would like to thank the following persons for taking an interest and discussing this concept with me, giving good advice and criticisms being of great help and encouragement.

- Walter C. Grantz, worldwide expert on immersed tunnels

- Bernt Jakobsen, international expert on oil platforms, all aspects

- Kaare Flaate, former Director of Road Research Laboratory, Norway

- Karl Melby, Wilhelm B. Klaveness and Svein K.Hovland

- A special thanks to Arild W.Solerød for making the drawing of tunnel system, much better than the ideas I gave him in 2003.

\section{References}

No references, proposed tunnel structure is authors idea. 